\title{
A balancing act: mechanisms by which the fetus avoids rejection by the maternal immune system
}

\author{
J C Warning, S A McCracken and J M Morris ${ }^{1}$ \\ Department of Perinatal Research, Kolling Institute of Medical Research, University of Sydney at Royal North Shore \\ Hospital, Sydney, New South Wales 2065, Australia and ${ }^{1}$ Department of Obstetrics and Gynaecology, Northern \\ Clinical School, University of Sydney, Sydney, New South Wales 2065, Australia
}

Correspondence should be addressed to J M Morris; Email: jmorris@med.usyd.edu.au

\begin{abstract}
Successful pregnancy requires strict temporal regulation of maternal immune function to accommodate the growing fetus. Early implantation is facilitated by inflammatory processes that ensure adequate vascular remodeling and placental invasion. To prevent rejection of the fetus, this inflammation must be curtailed; reproductive immunologists are discovering that this process is orchestrated by the fetal unit and, in particular, the extravillous trophoblast. Soluble and particulate factors produced by the trophoblast regulate maternal immune cells within the decidua, as well as in the periphery. The aim of this review is to discuss the action of recently discovered immunomodulatory factors and mechanisms, and the potential effects of dysregulation of such mechanisms on the maternal immune response that may result in pregnancy loss or preeclampsia.

Reproduction (2011) $141715-724$
\end{abstract}

\section{Introduction}

Throughout human pregnancy, the genetically 'foreign' semi-allogeneic fetus and placenta evade maternal immune responses. Fetal survival requires significant regulation of the maternal immune system but not such as to compromise maternal immune protection. The mechanisms that regulate maternal 'tolerance' have been the subject of burgeoning interest since the seminal paper by Medawar (1953) published over 50 years ago. How these mechanisms are coordinated remains somewhat elusive, hindered by assumptions that, in their attempt to provide lucid explanations, have adopted simplified paradigms. For many years, it was posited that pregnancy is purely a Th2 phenomenon (Wegmann et al. 1993), i.e. maternal CD $4^{+}$T helper type I (Th1) cells that mediate allospecific cytotoxic responses being inhibited during pregnancy to prevent rejection of the fetal allograft, while the number of Th2 cells that mediate antibody responses are increased, preventing complete immunosuppression. Th1 cytokine responses are abrogated through downregulation of nuclear factor $\kappa B$ (NFKB) during pregnancy (McCracken et al. 2003). This suppression of T-cell-mediated cytotoxic (Th1) responses is reflected in the frequent amelioration of cell-mediated autoimmune disorders such as rheumatoid arthritis. However, recent data indicate that success in early pregnancy requires augmentation of cytokines traditionally associated with Th1 responses. The maternal immune system must therefore be subject to strict control that is temporally regulated in response to the changing needs of the developing fetus.

Over the past 20 years, the role of cells of the innate arm of the maternal immune system and the immunologic function of fetal-derived trophoblast have assumed importance for the development and protection of the fetoplacental unit. During pregnancy, fetal-derived trophoblast and membranes are in direct contact with decidual maternal immune effector cells, the majority of which are from the innate arm, predominantly decidual natural killer (dNKs) cells and macrophages. This indicates that the maternal-fetal interface is not an immune-privileged site, and multiple mechanisms originating from both mother and fetus contribute to the development and maintenance of tolerance (Fig. 1).

We discuss recent discoveries of mechanisms employed by fetal-derived trophoblast that indicate communication between fetus and maternal immune cells is necessary for pregnancy success. In contrast to the notion of simple maternal immune suppression, successful pregnancy is achieved through the fetoplacental unit not only inducing maternal tolerance but also enabling certain provoked inflammatory responses that facilitate trophoblast invasion. Understanding the phenomenon of the maternal-fetal allograft may assist in the understanding of pregnancy success and complications of pregnancy, and lead to the discovery of predictive biomarkers and novel therapeutic targets. 

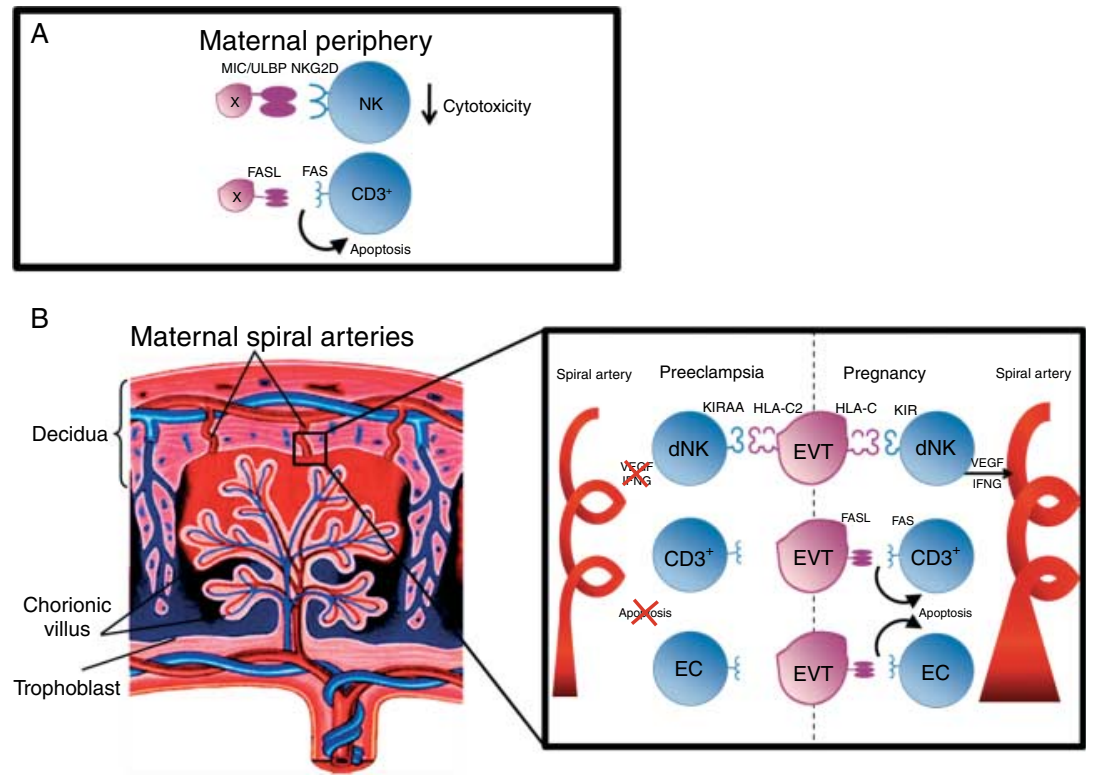

Figure 1 Trophoblast promotes vascular remodeling and maternal tolerance both locally at the maternal-fetal interface and in the periphery. (A) Trophoblast shed microparticles such as exosomes $\left(\mathrm{x}\right.$ ) resulting in systemic paternal antigen exposure, driving $\mathrm{T}_{\text {reg }}$ proliferation. Exosomes express MIC and ULBP, both ligands for the NK receptor NKG2D, inhibiting maternal NK cytolysis when bound. Exosomes also express FASL, promoting apoptosis of peripheral activated maternal lymphocytes. (B) Extravillous trophoblast (EVT) invades uterine spiral arteries and replaces endothelium, aiding vascular remodeling critical for sufficient blood supply to the fetus. EVT expresses HLA-C. Upon binding the NK receptor, KIR, HLA-C inhibits cytolysis, and stimulates secretion of angiogenic and growth factors. This facilitates spiral artery remodeling and promotes trophoblast invasion. In preeclampsia, the combination of maternal KIRAA and fetal HLA-C2 is more common, inhibiting the production of angiogenic factors. EVT expresses FASL, promoting apoptosis of FAS-bearing activated CD ${ }^{+} \mathrm{T}$ cells and endothelial cells (EC), protecting against maternal immune activation, while enabling placental invasion and spiral artery remodeling. The expression of FASL on EVT may be reduced in preeclampsia.

\section{The maternal immune system: preconceptually prepared?}

Epidemiological evidence suggests that tolerance to paternal antigens is facilitated by preconceptual exposure (Dekker \& Robillard 2007). In murine models, seminal fluid primes the maternal immune response, resulting in expansion of paternal antigen-specific immune-tolerant cells (Moldenhauer et al. 2009), and has a favorable cytokine composition, postulated to be mediated by transforming growth factor- $\beta$ (TGFB), to promote tolerance (Robertson et al. 2009). In humans, prior exposure may also occur, potentially protecting against pregnancy-induced hypertension (Robillard et al. 1994). Preeclampsia, a multi-system human pregnancyspecific disorder characterized by de novo hypertension and proteinuria, is a condition that involves insufficient invasion of the maternal uterine vasculature by extravillous trophoblast (EVT). Epidemiological observations that preeclampsia is more likely with first pregnancies, and in women undergoing IVF with donor sperm, compared with those using partner sperm (Kyrou et al. 2010), support the view that risk is attributed to the assumed minimal pre-exposure to paternal antigens (Saito et al. 2007). While the clinical symptoms of preeclampsia do not appear prior to 20 weeks gestation, placental histology indicates impaired trophoblast invasion and spiral artery remodeling in early pregnancy. Vascular remodeling depends on inflammatory mediators, indicating that preeclampsia is a result of maternal immune dysfunction. It remains to be established whether this dysfunction arises out of aberrant paternal antigen presentation.

\section{The maternal-fetal interface: trophoblast triggers tolerance?}

Following implantation, immune recognition of the fetus occurs primarily at the maternal-fetal interface in the first trimester, due to direct invasion of EVT into the decidualized endometrium and inner third of the myometrium. The establishment of placentation is facilitated through early interactions between EVT and maternal cells, predominantly of the innate immune arm.

\section{Innate immune mechanisms}

In the first trimester of pregnancy, $30-40 \%$ of the decidua consists of maternal immune cells, of which most are innate dNK cells $(70 \%)$, with macrophages $(<30 \%)$, T cells $(<20 \%)$ and dendritic cells $(\mathrm{DC} ;<2 \%)$ also present (Loke et al. 1995). 
NK cells are cytotoxic, instrumental in clearing virus-infected cells and tumor cells. Their activity is determined by engagement of their activating or inhibitory receptors. dNKs differ from their peripheral counterpart, not only in phenotype but also in apparent function. dNKs are typically CD56 $6^{\text {bright }} / \mathrm{CD} 16^{-}{ }^{-}$, while peripheral NKs are CD56 $6^{\mathrm{dim}} / \mathrm{CD} 16^{+}$(King et al. 1996). CD16 is directly involved in triggering the lysis of target cells. The absence of CD16 expression on dNKs results in reduced cytotoxicity in these cells, switching function to cytokine production. The vast majority of dNKs are located at the site of trophoblast invasion - the decidua basalis. Their growth factors and chemokines augment invading trophoblast and promote vascular remodeling (Hiby et al. 2004), while inhibition of dNK cells increases the likelihood of preeclampsia. A reduction in dNK cell numbers is associated with intrauterine growth restriction (IUGR; Williams et al. 2009); IUGR is indicative of limited trophoblast invasion.

dNK cells can be activated or inhibited by ligands expressed by invading EVT, the predominant one being paternal HLA-C, the only polymorphic major histocompatibility complex (MHC)-Class I molecule expressed on the surface of trophoblast. HLA-C molecules are recognized by the killer Ig-like receptor (KIR) family on the surface of NK cells. The proportion of dNKs expressing KIR is higher than their peripheral blood counterpart, indicating that dNKs have an increased capacity for communicating with invading EVT. KIR can be divided into two haplotypes: haplotype A contains only inhibitory KIR, while haplotype B contains inhibitory and activating KIR. These KIR distinguish HLA-C via two polymorphisms, and as such, all HLA-C allotypes can be classed as either C1 or C2. Particular HLA-C and KIR combinations were recently discovered to be associated with preeclampsia (Hiby et al. 2004, Moffett \& Hiby 2007). Women with preeclampsia were more likely to have the inhibitory KIR AA haplotype combined with an HLA-C2 infant; HLA-C2 on trophoblast will only engage the inhibitory KIR2DL1 receptor.
This may lead to inhibition of angiogenic factors produced by $d N K$ cells, resulting in the failure of vascular remodeling that precedes the onset of preeclampsia (Hanna et al. 2006).

NKG2D is an activating receptor on the surface of NKs, as well as cytotoxic CD8 ${ }^{+}$and $\gamma \delta$ T cells. NKG2D binds to MHC-I chain-related proteins (MIC) A and B, and to UL-16-binding protein (ULBP), leading to perforin-mediated cytotoxicity. Soluble MIC binds NKG2D and downregulates its expression on CTL and NK, leading to immunosuppression. Exosomes derived from early placenta explants express MIC and ULBP, and initiate internalization of NKG2D in dNKs, CD8 ${ }^{+}$ and $\gamma \delta \mathrm{T}$ cells, reducing cell surface expression and subsequent cytotoxic capacity (Hedlund et al. 2009). Interestingly, NKG2D is ubiquitously expressed on dNKs (Apps et al. 2008) and while ULBP is constitutively expressed by syncytiotrophoblast intracellularly, it is not detectable on the cell surface (Hedlund et al. 2009). Findings from a recent study indicate the ULBP expression on lymphoma cells render them susceptible to cytotoxic killing by $\gamma \delta \mathrm{T}$ cells (Lanca et al. 2010), indicating that the internalization of this protein in trophoblast is a controlled mechanism inhibiting dNK-mediated cytolysis. Questions such as 'What mechanism regulates the expression of this protein in trophoblast, and is ULBP expression on trophoblast upregulated in preeclampsia?' are yet to be answered.

Thus, NK cells at the maternal-fetal interface are functionally active. Rather than being a threat to pregnancy, the dNK cell is recruited and harnessed by the trophoblast via the production of chemokines and specific ligands. Consequently, the dNK cell secretes important cytokines and growth factors (Hanna et al. 2006) such as vascular endothelial growth factor (VEGF) and interferon- $\gamma$ (IFNG; see Box 1 ), promoting vascular remodeling and invasion of the trophoblast into the uterus in a highly regulated manner. Inhibition of the activity of $d N K$ at the maternal-fetal interface

\section{Box 1 IFNG: pregnancy friend or foe?}

In early pregnancy, dNKs produce IFNG. This cytokine acts in an autocrine manner on dNKs, stimulating further production of IFNG, as well as VEGF, ANGPT2 (AngII), and PGF, creating a proangiogenic milieu. IFNG also activates nitric oxide synthase (NOS) that produces nitric oxide (NO), a compound that stimulates vasodilation and inhibits smooth muscle cell proliferation. Importantly, IFNG can have either proliferative or cytotoxic effects, determined primarily by the relative density of its two receptors: IFNGR1 and IFNGR2. These two receptors are expressed on the surface of trophoblast throughout pregnancy, while the expression of IFNG is only present in early pregnancy. Interestingly, IFNGR1 expression seems to be stable throughout pregnancy, while IFNGR2 expression is low in early pregnancy and increases in late pregnancy. The expression of IFNGR2 seems to be dysregulated in PET as it is similar to that of early pregnancy (Banerjee et al. 2005). This may be a result of the hypoxic placenta, as low oxygen tension and NO modulates IFNGR2 density on T cells. Chronic activation with IFNG can inhibit NOS, leading to vasoconstriction, hypertension, and IUGR. Increased IFNG production has been noted in decidual cells in preeclampsia (Wilczynski et al. 2003). 
may lead to dysregulation of vascular remodeling, limiting the depth of trophoblast invasion as observed in preeclampsia.

\section{Adaptive immune mechanisms}

The close proximity between maternal cells and fetal trophoblast would also be expected to activate adaptive immune responses, comprising of B and T lymphocytes, which are highly specific and primarily delayed. Subsequent long-lasting memory enables lymphocytes to respond more rapidly and robustly upon repeated antigen exposure. Adaptive immunity is pivotal in allograft rejection, mediated mainly by $\mathrm{CD} 8^{+}$cytotoxic $\mathrm{T}$ cells. Adaptive immune function is necessarily restrained during pregnancy to protect the fetal allograft. This restraint is thought to be primarily mediated by abrogation of Th1 responses and augmentation of regulatory $\mathrm{T}\left(\mathrm{T}_{\text {reg }}\right)$ cells.

On encountering engaged antigen-presenting cells (APC) such as B cells or DC, $\mathrm{CD} 4^{+} \mathrm{T}$ cells may differentiate into $T$ helper (Th) lymphocytes or $T_{\text {reg }}$ cells. The type of APC, coupled with the cytokine milieu and the dose of antigen, determines the differentiation pathway of the naïve T cell. During pregnancy, the dose of antigen is measured as the expression of non-maternal (i.e. paternally) inherited proteins on trophoblast at the maternal-fetal interface. The trophoblast thus influences the differentiation of maternal $\mathrm{CD} 4{ }^{+} \mathrm{T}$ lymphocytes into Th1, Th2, Th17 or $\mathrm{T}_{\text {reg }}$ cells.

Th1 cells, driven by the presence of interleukin 12 (IL12), promote cytotoxicity through the production of IL2 and IFNG, and tend to be inhibited in clinically normal pregnancies (McCracken et al. 2004). Th2 cells are predominant in peripheral blood in second and third trimesters of healthy pregnancy (Saito et al. 1999). Th2 cells are driven by the presence of IL4 and IL10, promote antibody responses and produce IL4, 5, and 10, protecting against rejection of the allogeneic fetus by inhibiting the induction of Th1 cells (Fig. 2).

$\mathrm{T}_{\text {reg }}$ cells are a major class of $\mathrm{CD} 4^{+} \mathrm{T}$ cells, driven to differentiate when binding their cognate antigen in the presence of TGFB in the absence of IL6. $\mathrm{T}_{\text {regs }}$ suppress activation of the immune system. Normal human pregnancy is characterized by increased numbers of $\mathrm{T}_{\text {reg }}$ in the periphery and at the maternal-fetal interface (Heikkinen et al. 2004, Sasaki et al. 2004, Somerset et al. 2004, Tilburgs et al. 2008), while in preeclampsia, $T_{\text {regs }}$ are reduced in number at the maternal-fetal interface (decidual FOXP3 ${ }^{+} / \mathrm{CD}^{+}{ }^{+}$; Sasaki et al. 2007) and in the periphery $\left(\mathrm{CD}^{+} / \mathrm{CD} 25^{\text {bright, }}\right.$; Darmochwal-Kolarz et al. 2007). Interestingly, the latter study also describe an increase in memory $\left(\mathrm{CD}^{+} / \mathrm{CD}^{2} 5 \mathrm{RO}^{+}\right) \mathrm{T}$ cells, indicating previous antigenic stimulation and activation of $\mathrm{T}$ cells, and an increase in $\mathrm{CD}^{+}{ }^{+} \mathrm{CD} 25^{+} \mathrm{T}$ cells in women with preeclampsia (Darmochwal-Kolarz et al. 2007). A recent study supports these data, and makes a strong case for the importance of maternal $\mathrm{T}_{\text {reg }}$ development in the maintenance of healthy pregnancy (Santner-Nanan et al. 2009). This importance was first posited by Aluvihare et al. (2004) in a murine model, where depletion of these cells led to pregnancy loss, and verified in a murine abortion model, where adoptive transfer of $\mathrm{T}_{\text {regs }}$ from normal pregnant mice completely rescues fetal rejection in abortion-prone recipients (Zenclussen et al. 2005). Santner-Nanan et al. (2009) also discovered that healthy pregnancy is associated with a decrease in Th17 cells, while this pro-inflammatory CD4 ${ }^{+}$ cell subset was increased in women with preeclampsia. This is not unexpected, as Th17 cells have been implicated in autoimmune and inflammatory pathologies such as

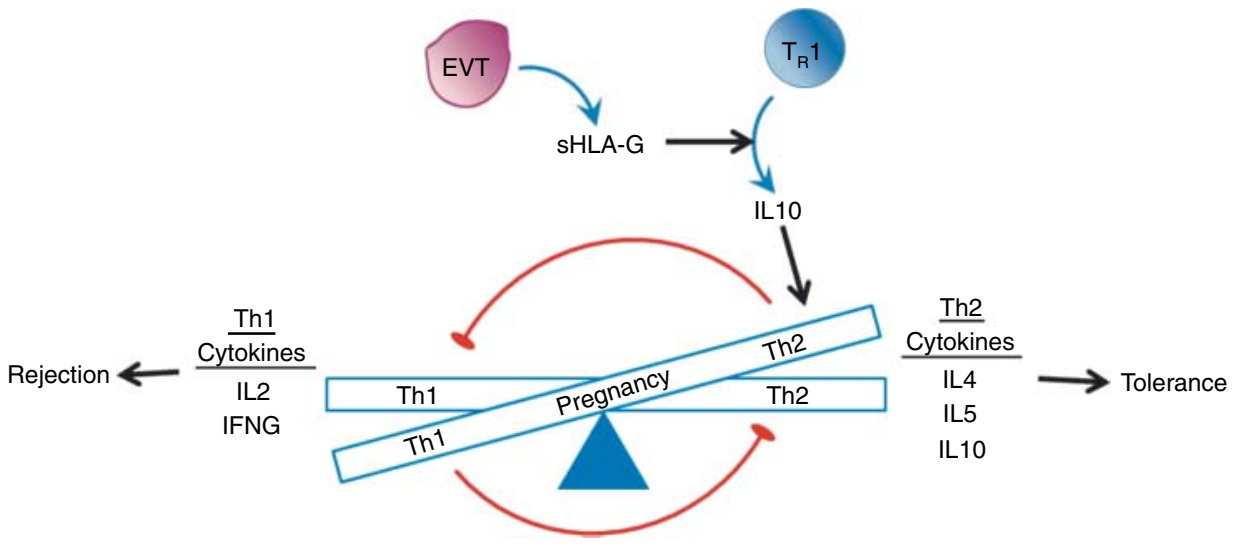

Figure $2 \mathrm{CD}^{+}{ }^{+} \mathrm{T}$ cells can differentiate into type 1 (Th1) or type 2 (Th2) helper cells. In the presence of proinflammatory cytokine IL12 and increased quantity of antigen, $\mathrm{CD} 4{ }^{+} \mathrm{T}$ cells differentiate into Th1 cells, important in cell-mediated immunity and protecting against viral infection. Th1 cells mediate allograft rejection. In the presence of IL4 and IL10, and low level of antigen, CD4 ${ }^{+} \mathrm{T}$ cells differentiate into Th2 cells, important in cell activation and mediate allergic responses. Th1 and Th2 cells mutually inhibit each other. Extravillous trophoblast secretes soluble HLA-G (HLA-G), inducing regulatory type $1 \mathrm{~T}$ cells $\left(\mathrm{T}_{\mathrm{R}} 1\right)$ to produce IL 10 , promoting maternal tolerance. 


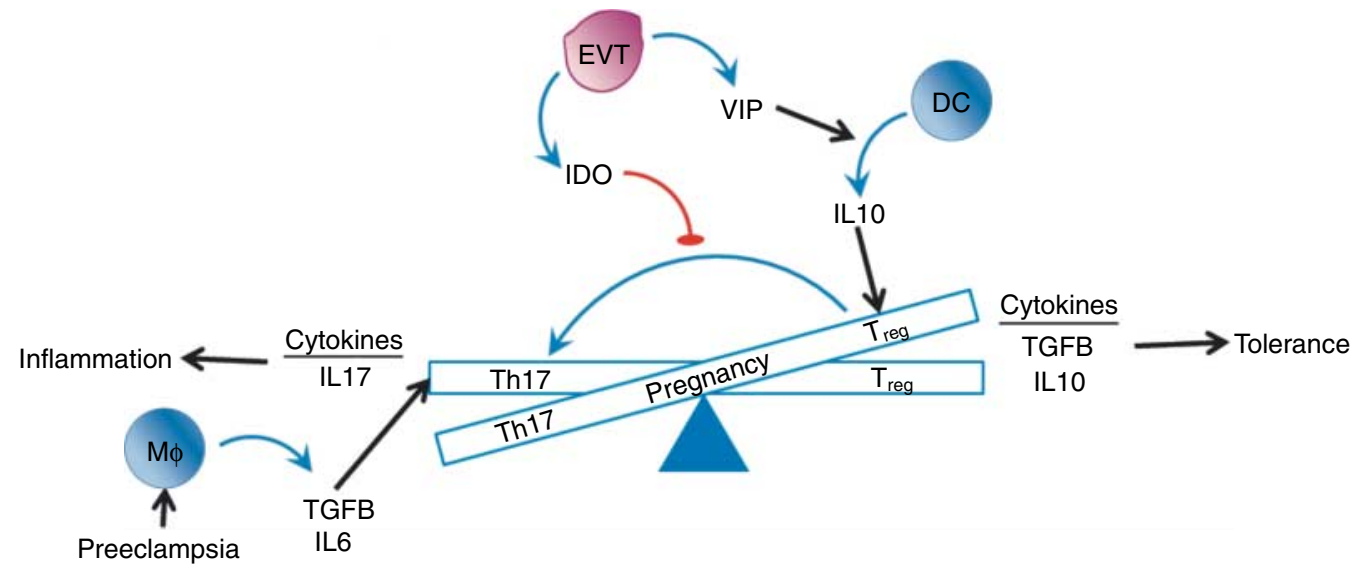

Figure 3 The plasticity of $\mathrm{T}_{\text {regs }}$ and Th17 cells. TGFB drives the differentiation of $\mathrm{T}_{\text {regs }}$ in the absence of IL6 in clinically normal pregnancies. In pregnancies affected by preeclampsia, maternal monocytes produce both IL1B and IL6, driving the differentiation of Th17 cells and subsequent production of IL17. These cells are implicated in transplant rejection and autoimmune disease. $\mathrm{T}_{\text {regs }}$ are able to switch to a Th17 phenotype; however, this is inhibited by the presence of indoleamine-2,3-dioxygenase (IDO), a molecule expressed by extravillous trophoblast (EVT). EVT also expresses vasoactive intestinal peptide (VIP), stimulating the production of maternal dendritic cells (DC) to produce IL10, promoting $\mathrm{T}_{\text {reg }}$ differentiation.

multiple sclerosis (Matusevicius et al. 1999) and rheumatoid arthritis (Shen et al. 2009), and monocytes isolated from women with preeclampsia constitutively secrete higher levels of IL1B and IL6 - both these cytokines drive Th17 development (Luppi \& Deloia 2006).

Th17 cells produce IL17 (Fig. 3), a proinflammatory cytokine also produced by adaptive $\mathrm{CD} 4^{+}$and $\mathrm{CD} 8^{+} \mathrm{T}$ cells and innate monocytes and NKT cells (Cua \& Tato 2010). In early pregnancy, IL17 production is restricted to $\mathrm{CD} 4{ }^{+} \mathrm{T}$ cells in both the periphery and decidua (Ito et al. 2010). The plasticity of immune responses is demonstrated by the discovery that $\mathrm{T}_{\text {regs }}$ can switch to a Th17 phenotype in the presence of inflammatory stimuli and cytokines (Koenen et al. 2008, Chaudhry et al. 2009), and this switch is suppressed by indoleamine-2, 3-dioxygenase (IDO; Baban et al. 2009), a molecule expressed on EVT.

\section{Fetal-derived factors}

\section{HLA-C}

As discussed, HLA-C is the only classical HLA Class I molecule expressed on trophoblast. HLA-C is necessary for antigenic presentation to $\mathrm{CD} 8^{+} \mathrm{T}$ cells. Interestingly, HLA-C-discordant pregnancies tend to have increased numbers of fetus-specific CD4 ${ }^{+} \mathrm{CD} 25^{\text {bright }} \mathrm{T}_{\text {reg }}$ cells, perhaps to suppress T-cell activation driven by discordant HLA-C expression (Tilburgs et al. 2009), while HLA-concordant pregnancies are associated with an increased risk of spontaneous abortion (Ober et al. 1998), indicating a degree of maternal immune stimulation is necessary for successful pregnancy. HLA alloantigen recognition may also enhance production of hormones and growth factors such as hCG (Harbour-McMenamin et al. 1986) and LIF (Nasef et al. 2008).

\section{HLA-G}

HLA-G, a non-classical Class I molecule, is also expressed on EVT. HLA-G modulates alloreactive $\mathrm{T}$ cells by downregulating CD4 and CD8 expression, increasing the proportion of $\mathrm{HLA}-\mathrm{DR}^{+} \mathrm{T}$ cells, and generating suppressor $\mathrm{T}$ cells, termed induced IL10producing type I $\mathrm{T}_{\text {regs }}$ cells (Tr1), in an IL10-dependent manner (Naji et al. 2007, Gregori et al. 2009). Tr1 cells secrete IL10 and TGFB that are able to suppress cytolytic responses without cell contact. This may provide a positive feedback loop in maintaining maternal tolerance, as membrane-bound HLA-G and its inhibitory receptor Ig-like transcript (ILT)-4 are upregulated in chronic antigen stimulation in the presence of IL10. Interestingly, an increase in soluble HLA-G in plasma correlates with an increase in IL10 and development of suppressor cells, and is strongly associated with graft survival (Naji et al. 2007). As the fetus can be considered an allograft, its production of membrane-bound and soluble HLA-G may be promoting maternal T-cell tolerance both locally and systemically.

HLA-G is both membrane-bound and secreted as soluble protein. Each can interact with its three inhibitory receptors: ILT-2, ILT-4, and KIR 2DL4 on the surface of NK cells, APC and T cells (see Hunt et al. (2005) for review). The interaction between HLA-G and its receptors protects the trophoblast against allogeneic NK and CTL-mediated cytolysis. Soluble HLA-G binds KIR2DL4, leading to the secretion of angiogenic factors 
important in vascular remodeling during early pregnancy. Only a subset of dNKs expresses ILT-2, and this subset of NKs are inhibited by HLA-G, diminishing dNK production of growth factors IL8, IP-10, VEGF, and placental growth factor (PGF), providing a maternal mechanism to control trophoblast invasion (Hanna et al. 2006).

\section{The role of FAS/FASL}

Trophoblast cells in early healthy pregnancy also express both FAS and FASL, potentially rendering them susceptible to FAS-mediated apoptosis. The presence of FASL (CD95L) on trophoblast plays an active role in the deletion of FAS (CD95)-bearing activated T-cells. Trophoblast cells induce apoptosis of $\mathrm{CD} 95^{+} \mathrm{T}$-cells in vitro, and the gld mouse that lacks functional CD95 has increased T-cell infiltrates at the maternal-fetal interface and is associated with increased fetal loss (Hunt et al. 1997). It is of note that soluble HLA-G upregulates $\mathrm{CD} 95 \mathrm{~L}$ expression on activated $\mathrm{CD} 8^{+} \mathrm{T}$ cells, triggering apoptosis in vitro (Fournel et al. 2000). The expression of FASL on trophoblast also facilitates apoptosis of endothelial cells, perhaps enabling the invasion and remodeling of maternal spiral arteries - limited data indicates reduced expression of FASL on trophoblast from pregnancies affected by preeclampsia (Eide et al. 2007).

\section{IDO and immune suppression}

Amino acid deprivation as a regulator of lymphocyte responses has long been implicated in immunosuppression at the maternal-fetal interface (Munn et al. 1998). IDO depletes L-tryptophan, inhibiting T-cell proliferation, and is highly expressed on EVT (Honig et al. 2004). IDO may also be released by trophoblast, as conditioned media derived from trophoblast or villous explant cultures inhibit T-cell proliferation, while inhibiting IDO or adding tryptophan partly restored T-cell proliferation (Dong et al. 2008).

IDO also has physiological importance during pregnancy, as decreased levels of tryptophan also results in vasodilation, via decreased serotonin. This fact raised controversy as to which role is more relevant to pregnancy success, as T-cell-mediated pregnancy loss occurs when IDO is inhibited (Munn et al. 1998). Bonney \& Matzinger (1998) state, it is their danger model that explains the immune activation when blocking IDO, as this increases reactive oxygen species intermediates, which activate NFKB and stimulate local macrophages, which in turn initiate the T-cell immune response. DC can also produce IDO, leading to the activation and maintenance of suppressor $\mathrm{T}_{\text {regs }}$ (Chen et al. 2008).

Decidual CD14 ${ }^{+}$myelomonocytic cells are found in close proximity to dNK cells. A recent study indicates that crosstalk between these two cell types at the maternal-fetal interface may be responsible for the induction of $\mathrm{T}_{\text {reg }}$ cells (Vacca et al. 2010). Contact with dNK cells results in IFNG-mediated IDO expression in $\mathrm{dCD} 4^{+}$cells, which in conjunction with TGFB promotes the development of $\mathrm{T}_{\text {reg }}$ cells (Vacca et al. 2010). The peripheral counterparts of these cells were not able to similarly drive $\mathrm{T}_{\mathrm{reg}}$-cell development. This confirms findings of previous studies that NK cells found within the decidual compartment are functionally distinct from peripheral NK cells, and that dNK cells play an important role in mediating immune tolerance during pregnancy.

\section{Anti-inflammatory VIP}

Vasoactive intestinal peptide (VIP) is a neuropeptide expressed in trophoblast (Marzioni et al. 2005), and contributes to smooth muscle relaxation and vasodilation in the uterus. VIP also has anti-inflammatory effects and, like progesterone, promotes a Th2 shift through the stimulation of IL10. DCs differentiated in the presence of VIP induce $T_{\text {regs, }}$ inhibiting allogeneic CD4 responses and increasing TGFB, suggesting a dual responsibility at the maternal-fetal interface (Fraccaroli et al. 2009).

Thus, maternal recognition of the fetal allograft seems to be necessary for the development and maintenance of a healthy pregnancy, with activation at least within maternal innate cells at the maternal-fetal interface facilitating vascular remodeling.

\section{Systemic strategies}

Changes in maternal peripheral blood indicate that pregnancy is associated with a mild yet sustained systemic inflammatory response (Sacks et al. 1999). Monocytes display increased activation, and this activation seems to be further exaggerated in preeclampsia (Redman et al. 1999, Redman \& Sargent 2004, Luppi \& Deloia 2006). It is of note that preeclampsia has recently been found to be associated with an increase in circulating placenta-derived microparticles (Goswami et al. 2006, Lok et al. 2008) and that these microparticles stimulate inflammatory responses in monocytes (Germain et al. 2007, Messerli et al. 2010).

Systemic release of paternal antigen throughout pregnancy may be necessary to maintain $\mathrm{T}_{\text {reg }}$ populations (Somerset et al. 2004, Zenclussen et al. 2010), mediating tolerance towards the semi-allogeneic fetus and limiting the maternal systemic inflammatory response. Interestingly, pregnant mice accept grafts expressing paternal-derived fetal antigen (Tafuri et al. 1995); paternal antigen presentation may be required for the maintenance of paternal antigen-specific $T_{\text {regs, }}$ as once pregnancy (and thus paternal antigen exposure) ceases, tolerance to paternal grafts also ceases (Tafuri et al. 1995). Trophoblast shedding and secretion of 
microparticles occur from second trimester, facilitating systemic exposure to paternal-derived antigen. Systemic exposure also occurs via fetal cell microchimerism, frequently described, though yet to be mechanistically explained. Fetal cells can persist in maternal blood and tissue, and in some studies, association of fetal cells with autoimmune disease have been reported, perhaps indicating a pathological tolerance in the maternal immune system (Lambert et al. 2002). However, recent data suggest that fetal cells may infiltrate injured maternal tissue as a repair mechanism (Khosrotehrani \& Bianchi 2005, Sunami et al. 2010).

Other circulating microvesicles include exosomes that are $30-100 \mathrm{~nm}$, formed and released through the late endosomal compartment by many cell types, including syncytiotrophoblast. They carry membrane-bound and cytosolic proteins, mRNA, microRNA, and bioactive lipids, and are capable of transmitting pathogens. As a result, exosomes mimic actions of their parent cell; trophoblast-derived exosomes possess immunesuppressing capabilities. Placental-derived exosomes are found in the peripheral blood of pregnant women, a potential explanation on how pregnancy results in systemic immune suppression (Sabapatha et al. 2006). Indeed, such exosomes express FASL and programmed death-1 ligand (PD-L1), a pro-apoptotic protein that binds PD-1 on the surface of activated maternal lymphocytes, removing them from the maternal circulation. In addition, T-cell activation requires expression of the $\mathrm{CD} 3 \zeta$ chain of the T-cell receptor. Exosomes derived from ovarian carcinoma cells and pregnant serum suppress $\mathrm{CD} 3 \zeta$ expression in T-cell lines (Taylor \& Gercel-Taylor 2005, Taylor et al. 2006), perhaps mediating the suppression of TCR/CD3 $\zeta$ expression seen in pregnancy (Lam et al. 2003).

During pregnancy, a woman's body is exposed to immense physiological stress. Under normal conditions, following cell stress or tissue damage, molecules usually located within the cell are released and can bind pattern recognition receptors (PRRs) on the surface of innate immune cells, triggering inflammation. These molecules are referred to as danger-associated molecular patterns (DAMP; Seong \& Matzinger 2004). ATP is one such molecule, present in high concentrations within all cells and released rapidly from the cell following exposure to trauma or oxidants. Interestingly, moderate release of ATP has an immunosuppressive anti-inflammatory effect, activating the $\mathrm{P} 2 \mathrm{Y} 11$ receptor, leading to partial maturation of DC and differentiation towards a Th2 phenotype (Marteau et al. 2004). Increased levels of released ATP activate the low-affinity P2X7 receptor, causing massive release of pro-inflammatory factors, including IL1B, IL18, IL6, and TNF, and reactive oxygen species, and can involve activation of the inflammasome. Non-apoptotic cell death (which may restrict trophoblast invasion in the presymptomatic stage of preeclampsia) results in higher levels of ATP in the extracellular milieu. Extracellular ATP inhibits LPSstimulated production of the immunosuppressive sHLA-G, via the P2X receptor (Rizzo et al. 2009). The $\mathrm{P} 2 \mathrm{X} 7$ receptor has been implicated in the production of tissue factor-expressing microparticles (Baroni et al. 2007), and MHC Class II-expressing exosomes (Qu et al. 2009). In rat models, $\mathrm{P} 2 X 7$ receptor expression in myometrium is associated with delivery, both term and preterm (Urabe et al. 2009), while in glomeruli, its expression is associated with hypertension. Whether this receptor is present on decidual NKs or DCs during pregnancy and whether expression levels change in pregnancy-related pathology such as preeclampsia are unknown and deserving of investigation.

\section{Conclusion}

Pregnancy is characterized by mild systemic immunosuppression and inflammation. Traditionally, the fetalmaternal interface was likened to a graft-host interaction. It is becoming more apparent that pregnancy is now a co-dependent, regulatory interaction between the mother and developing fetus. The placenta actively produces and secretes various immunomodulatory factors to prevent rejection of the histoincompatible fetus by the innate and adaptive maternal immune system. Indeed, maternal immune recognition of the fetus occurs throughout uncomplicated pregnancies, and activated $\mathrm{CD}^{+} \mathrm{T}$ cells are present at the maternalfetal interface. Apoptosis is induced in these cells by the FASL-expressing EVT cells.

Immunological tolerance at the maternal-fetal interface requires tight temporal regulation between the immune and vascular networks, involving multiple mechanisms. These mechanisms perform a balancing act to regulate trophoblast invasion. Indeed, angiogenesis and trophoblast invasion are immunologically active processes; rather than 'escaping' maternal recognition, the fetus harnesses maternal immune surveillance mechanisms to facilitate survival and growth.

\section{Declaration of interest}

The authors declare that there is no conflict of interest that could be perceived as prejudicing the impartiality of the research reported.

\section{Funding}

This work was supported by a grant from the National Health and Medical Research Council, Australia to J M Morris (512168). 


\section{References}

Aluvihare VR, Kallikourdis M \& Betz AG 2004 Regulatory T cells mediate maternal tolerance to the fetus. Nature Immunology 5 266-271. (doi:10. 1038/ni1037)

Apps R, Gardner L, Traherne J, Male V \& Moffett A 2008 Natural-killer cell ligands at the maternal-fetal interface: UL-16 binding proteins, MHC class-I chain related molecules, HLA-F and CD48. Human Reproduction 23 2535-2548. (doi:10.1093/humrep/den223)

Baban B, Chandler PR, Sharma MD, Pihkala J, Koni PA, Munn DH \& Mellor AL 2009 IDO activates regulatory T cells and blocks their conversion into Th17-like $\mathrm{T}$ cells. Journal of Immunology $\mathbf{1 8 3}$ 2475-2483. (doi:10.4049/jimmunol.0900986)

Banerjee S, Smallwood A, Moorhead J, Chambers AE, Papageorghiou A, Campbell S \& Nicolaides K 2005 Placental expression of interferongamma (IFN-gamma) and its receptor IFN-gamma R2 fail to switch from early hypoxic to late normotensive development in preeclampsia. Journal of Clinical Endocrinology and Metabolism 90 944-952. (doi:10.1210/jc.2004-1113)

Baroni M, Pizzirani C, Pinotti M, Ferrari D, Adinolfi E, Calzavarini S, Caruso P, Bernardi F \& Di Virgilio F 2007 Stimulation of P2 (P2X7) receptors in human dendritic cells induces the release of tissue factorbearing microparticles. FASEB Journal 21 1926-1933. (doi:10.1096/fj. 06-7238com)

Bonney EA \& Matzinger P 1998 Much IDO about pregnancy. Nature Medicine 4 1128-1129. (doi:10.1038/2624)

Chaudhry A, Rudra D, Treuting P, Samstein RM, Liang Y, Kas A \& Rudensky AY 2009 CD4 + regulatory T cells control TH17 responses in a Stat3-dependent manner. Science 326 986-991. (doi:10.1126/science. 1172702)

Chen W, Liang X, Peterson AJ, Munn DH \& Blazar BR 2008 The indoleamine 2,3-dioxygenase pathway is essential for human plasmacytoid dendritic cell-induced adaptive $\mathrm{T}$ regulatory cell generation. Journal of Immunology 181 5396-5404.

Cua DJ \& Tato CM 2010 Innate IL-17-producing cells: the sentinels of the immune system. Nature Reviews Immunology 10 479-489. (doi:10. 1038/nri2800)

Darmochwal-Kolarz D, Saito S, Rolinski J, Tabarkiewicz J, Kolarz B, Leszczynska-Gorzelak B \& Oleszczuk J 2007 Activated T lymphocytes in pre-eclampsia. American Journal of Reproductive Immunology $\mathbf{5 8}$ 39-45. (doi:10.1111/j.1600-0897.2007.00489.x)

Dekker G \& Robillard PY 2007 Pre-eclampsia: Is the immune maladaptation hypothesis still standing? An epidemiological update Journal of Reproductive Immunology 76 8-16. (doi:10.1016/j.jri.2007. 03.015)

Dong M, Ding G, Zhou J, Wang H, Zhao Y \& Huang H 2008 The effect of trophoblasts on T lymphocytes: possible regulatory effector molecules - a proteomic analysis. Cellular Physiology and Biochemistry 21 463-472. (doi:10.1159/000129639)

Eide IP, Isaksen CV, Salvesen KA, Langaas M, Gunther CC, Iversen AC \& Austgulen R 2007 Fetal growth restriction is associated with reduced FasL expression by decidual cells. Journal of Reproductive Immunology $\mathbf{7 4}$ 7-14. (doi:10.1016/j.jri.2006.11.002)

Fournel S, Aguerre-Girr M, Huc X, Lenfant F, Alam A, Toubert A, Bensussan A \& Le Bouteiller P 2000 Cutting edge: soluble HLA-G1 triggers CD95/CD95 ligand-mediated apoptosis in activated $\mathrm{CD}^{+}$cells by interacting with CD8. Journal of Immunology $\mathbf{1 6 4}$ 6100-6104.

Fraccaroli L, Alfieri J, Larocca L, Calafat M, Roca V, Lombardi E, Ramhorst R \& Leiros CP 2009 VIP modulates the pro-inflammatory maternal response, inducing tolerance to trophoblast cells. British Journal of Pharmacology 156 116-126. (doi:10.1111/j.1476-5381. 2008.00055.x)

Germain SJ, Sacks GP, Sooranna SR, Sargent IL \& Redman CW 2007 Systemic inflammatory priming in normal pregnancy and preeclampsia: the role of circulating syncytiotrophoblast microparticles. Journal of Immunology 178 5949-5956.

Goswami D, Tannetta DS, Magee LA, Fuchisawa A, Redman CW, Sargent IL \& von Dadelszen P 2006 Excess syncytiotrophoblast microparticle shedding is a feature of early-onset pre-eclampsia, but not normotensive intrauterine growth restriction. Placenta 27 56-61. (doi:10.1016/j. placenta.2004.11.007)
Gregori S, Magnani CF \& Roncarolo MG 2009 Role of human leukocyte antigen-G in the induction of adaptive type 1 regulatory $\mathrm{T}$ cells. Human Immunology 70 966-969. (doi:10.1016/j.humimm.2009.07.022)

Hanna J, Goldman-Wohl D, Hamani Y, Avraham I, Greenfield C, Natanson-Yaron S, Prus D, Cohen-Daniel L, Arnon TI, Manaster I et al. 2006 Decidual NK cells regulate key developmental processes at the human fetal-maternal interface. Nature Medicine 12 1065-1074. (doi:10.1038/nm1452)

Harbour-McMenamin D, Smith EM \& Blalock JE 1986 Production of immunoreactive chorionic gonadotropin during mixed lymphocyte reactions: a possible selective mechanism for genetic diversity. PNAS 83 6834-6838. (doi:10.1073/pnas.83.18.6834)

Hedlund M, Stenqvist AC, Nagaeva O, Kjellberg L, Wulff M, Baranov V \& Mincheva-Nilsson L 2009 Human placenta expresses and secretes NKG2D ligands via exosomes that down-modulate the cognate receptor expression: evidence for immunosuppressive function. Journal of Immunology 183 340-351. (doi:10.4049/jimmunol.0803477)

Heikkinen J, Mottonen M, Alanen A \& Lassila O 2004 Phenotypic characterization of regulatory $\mathrm{T}$ cells in the human decidua. Clinical and Experimental Immunology 136 373-378. (doi:10.1111/j.13652249.2004.02441.x)

Hiby SE, Walker JJ, O'Shaughnessy KM, Redman CW, Carrington M, Trowsdale J \& Moffett A 2004 Combinations of maternal KIR and fetal HLA-C genes influence the risk of preeclampsia and reproductive success. Journal of Experimental Medicine 200 957-965. (doi:10.1084/ jem.20041214)

Honig A, Rieger L, Kapp M, Sutterlin M, Dietl J \& Kammerer U 2004 Indoleamine 2,3-dioxygenase (IDO) expression in invasive extravillous trophoblast supports role of the enzyme for materno-fetal tolerance. Journal of Reproductive Immunology 61 79-86. (doi:10.1016/j.jri.2003. 11.002)

Hunt JS, Vassmer D, Ferguson TA \& Miller L 1997 Fas ligand is positioned in mouse uterus and placenta to prevent trafficking of activated leukocytes between the mother and the conceptus. Journal of Immunology 158 4122-4128.

Hunt JS, Petroff MG, McIntire RH \& Ober C 2005 HLA-G and immune tolerance in pregnancy. FASEB Journal 19 681-693. (doi:10.1096/fj.042078rev)

Ito $M$, Nakashima $A$, Hidaka $T$, Okabe $M$, Bac ND, Ina $S$, Yoneda $S$, Shiozaki A, Sumi S, Tsuneyama K et al. 2010 A role for IL-17 in induction of an inflammation at the fetomaternal interface in preterm labour. Journal of Reproductive Immunology 84 75-85. (doi:10.1016/j.jri.2009. 09.005)

Khosrotehrani K \& Bianchi DW 2005 Multi-lineage potential of fetal cells in maternal tissue: a legacy in reverse. Journal of Cell Science 118 1559-1563. (doi:10.1242/jcs.02332)

King A, Burrows T \& Loke YW 1996 Human uterine natural killer cells. Nature Immunology 15 41-52.

Koenen HJ, Smeets RL, Vink PM, van Rijssen E, Boots AM \& Joosten I 2008 Human CD25highFoxp3pos regulatory T cells differentiate into IL-17-producing cells. Blood 112 2340-2352. (doi:10.1182/blood2008-01-133967)

Kyrou D, Kolibianakis EM, Devroey P \& Fatemi HM 2010 Is the use of donor sperm associated with a higher incidence of preeclampsia in women who achieve pregnancy after intrauterine insemination? Fertility and Sterility 93 1124-1127. (doi:10.1016/j.fertnstert.2008. 12.021)

Lam GK, Whitecar PW, Orton S, Boggess KA \& Taylor DD 2003 Differential expression of TCR-CD3 zeta as evidence for altered immunoregulation in preeclamptic versus normotensive women. American Journal of Obstetrics and Gynaecology 189 843-847. (doi:10.1067/S0002-9378 (03)00815-9)

Lambert NC, Lo YM, Erickson TD, Tylee TS, Guthrie KA, Furst DE \& Nelson JL 2002 Male microchimerism in healthy women and women with scleroderma: cells or circulating DNA? A quantitative answer Blood 100 2845-2851. (doi:10.1182/blood-2002-01-0295)

Lanca T, Correia DV, Moita CF, Raquel H, Neves-Costa A, Ferreira C, Ramalho JS, Barata JT, Moita LF, Gomes AQ et al. 2010 The MHC class Ib protein ULBP1 is a non-redundant determinant of leukemia/lymphoma susceptibility to gammadelta T-cell cytotoxicity. Blood $\mathbf{1 1 5}$ 2407-2411. (doi:10.1182/blood-2009-08-237123) 
Lok CA, Van Der Post JA, Sargent IL, Hau CM, Sturk A, Boer K \& Nieuwland R 2008 Changes in microparticle numbers and cellular origin during pregnancy and preeclampsia. Hypertension in Pregnancy $\mathbf{2 7}$ 344-360. (doi:10.1080/10641950801955733)

Loke YW, King A \& Burrows TD 1995 Decidua in human implantation. Human Reproduction 10 (Supplement 2) 14-21.

Luppi P \& Deloia JA 2006 Monocytes of preeclamptic women spontaneously synthesize pro-inflammatory cytokines. Clinical Immunology 118 268-275. (doi:10.1016/j.clim.2005.11.001)

Marteau F, Communi D, Boeynaems JM \& Suarez Gonzalez N 2004 Involvement of multiple P2Y receptors and signaling pathways in the action of adenine nucleotides diphosphates on human monocytederived dendritic cells. Journal of Leukocyte Biology 76 796-803. (doi:10.1189/jlb.0104032)

Marzioni D, Fiore G, Giordano A, Nabissi M, Florio P, Verdenelli F, Petraglia F \& Castellucci M 2005 Placental expression of substance Pand vasoactive intestinal peptide: evidence for a local effect on hormone release. Journal of Clinical Endocrinology and Metabolism 90 2378-2383. (doi:10.1210/jc.2004-1512)

Matusevicius D, Kivisakk P, He B, Kostulas N, Ozenci V, Fredrikson S \& Link H 1999 Interleukin-17 mRNA expression in blood and CSF mononuclear cells is augmented in multiple sclerosis. Multiple Sclerosis 5 101-104. (doi:10.1177/135245859900500206)

McCracken SA, Drury CL, Lee HS \& Morris JM 2003 Pregnancy is associated with suppression of the nuclear factor kappaB/lkappaB activation pathway in peripheral blood mononuclear cells. Journal of Reproductive Immunology 58 27-47. (doi:10.1016/S0165-0378(02) 00081-5)

McCracken SA, Gallery E \& Morris JM 2004 Pregnancy-specific downregulation of NF-kappa B expression in T cells in humans is essential for the maintenance of the cytokine profile required for pregnancy success. Journal of Immunology 172 4583-4591.

Medawar PB 1953 Some immunological and endocrinological problems raised by the evolution of viviparity in vertebrates. Symposia of the Society for Experimental Biology 7 320-328.

Messerli M, May K, Hansson SR, Schneider H, Holzgreve W, Hahn S \& Rusterholz C 2010 Feto-maternal interactions in pregnancies: placental microparticles activate peripheral blood monocytes. Placenta 31 106-112. (doi:10.1016/j.placenta.2009.11.011)

Moffett A \& Hiby SE 2007 How does the maternal immune system contribute to the development of pre-eclampsia? Placenta 28 (Supplement A) S51-S56. (doi:10.1016/j.placenta.2006.11.008)

Moldenhauer LM, Diener KR, Thring DM, Brown MP, Hayball JD \& Robertson SA 2009 Cross-presentation of male seminal fluid antigens elicits $\mathrm{T}$ cell activation to initiate the female immune response to pregnancy. Journal of Immunology 182 8080-8093. (doi:10.4049/ jimmunol.0804018)

Munn DH, Zhou M, Attwood JT, Bondarev I, Conway SJ, Marshall B, Brown C \& Mellor AL 1998 Prevention of allogeneic fetal rejection by tryptophan catabolism. Science 281 1191-1193. (doi:10.1126/science. 281.5380.1191)

Naji A, Le Rond S, Durrbach A, Krawice-Radanne I, Creput C, Daouya M, Caumartin J, LeMaoult J, Carosella ED \& Rouas-Freiss N 2007 $\mathrm{CD} 3{ }^{+} \mathrm{CD} 4$ low and $\mathrm{CD} 3{ }^{+} \mathrm{CD} 8$ low are induced by HLA-G: novel human peripheral blood suppressor T-cell subsets involved in transplant acceptance. Blood 110 3936-3948. (doi:10.1182/blood-2007-04083139)

Nasef A, Mazurier C, Bouchet S, Francois S, Chapel A, Thierry D, Gorin NC \& Fouillard L 2008 Leukemia inhibitory factor: Role in human mesenchymal stem cells mediated immunosuppression. Cellular Immunology 253 16-22. (doi:10.1016/j.cellimm.2008.06.002)

Ober C, Hyslop T, Elias S, Weitkamp LR \& Hauck WW 1998 Human leukocyte antigen matching and fetal loss: results of a 10 year prospective study. Human Reproduction 13 33-38. (doi:10.1093/humrep/13.1.33)

Qu Y, Ramachandra L, Mohr S, Franchi L, Harding CV, Nunez G \& Dubyak GR 2009 P2X7 receptor-stimulated secretion of MHC class II-containing exosomes requires the ASC/NLRP3 inflammasome but is independent of caspase-1. Journal of Immunology 182 5052-5062. (doi:10.4049/jimmunol.0802968)

Redman CW \& Sargent IL 2004 Preeclampsia and the systemic inflammatory response. Seminars in Nephrology 24 565-570. (doi:10. 1016/S0270-9295(04)00127-5)
Redman CW, Sacks GP \& Sargent IL 1999 Preeclampsia: an excessive maternal inflammatory response to pregnancy. American Journal of Obstetrics and Gynaecology 180 499-506. (doi:10.1016/S00029378(99)70239-5)

Rizzo R, Ferrari D, Melchiorri L, Stignani M, Gulinelli S, Baricordi OR \& Di Virgilio F 2009 Extracellular ATP acting at the P2X7 receptor inhibits secretion of soluble HLA-G from human monocytes. Journal of Immunology 183 4302-4311. (doi:10.4049/jimmunol.0804265)

Robertson SA, Guerin LR, Bromfield JJ, Branson KM, Ahlstrom AC \& Care AS 2009 Seminal fluid drives expansion of the $\mathrm{CD} 4{ }^{+} \mathrm{CD} 25^{+} \mathrm{T}$ regulatory cell pool and induces tolerance to paternal alloantigens in mice. Biology of Reproduction 80 1036-1045. (doi:10.1095/biolreprod. 108.074658)

Robillard PY, Hulsey TC, Perianin J, Janky E, Miri EH \& Papiernik E 1994 Association of pregnancy-induced hypertension with duration of sexual cohabitation before conception. Lancet 344 973-975. (doi:10.1016/ S0140-6736(94)91638-1)

Sabapatha A, Gercel-Taylor C \& Taylor DD 2006 Specific isolation of placenta-derived exosomes from the circulation of pregnant women and their immunoregulatory consequences. American Journal of Reproductive Immunology 56 345-355. (doi:10.1111/j.1600-0897.2006. 00435.x)

Sacks G, Sargent I \& Redman C 1999 An innate view of human pregnancy. Immunology Today 20 114-118. (doi:10.1016/S0167-5699(98)01393-0)

Saito S, Sakai M, Sasaki Y, Tanebe K, Tsuda H \& Michimata T 1999 Quantitiative analysis of peripheral blood Th0, Th1, Th2 and the Th1:Th2 cell ratio during normal human pregnancy and preeclampsia. Clinical and Experimental Immunology 117 50-555. (doi:10.1046/j.1365-2249. 1999.00997.x)

Saito S, Sakai M, Sasaki Y, Nakashima A \& Shiozaki A 2007 Inadequate tolerance induction may induce pre-eclampsia. Journal of Reproductive Immunology 76 30-39. (doi:10.1016/j.jri.2007.08.002)

Santner-Nanan B, Peek MJ, Khanam R, Richarts L, Zhu E, Fazekas de St Groth B \& Nanan R 2009 Systemic increase in the ratio between Foxp $^{+}$and IL-17-producing $\mathrm{CD} 4^{+} \mathrm{T}$ cells in healthy pregnancy but not in preeclampsia. Journal of Immunology 183 7023-7030. (doi:10. 4049/jimmunol.0901154)

Sasaki Y, Sakai M, Miyazaki S, Higuma S, Shiozaki A \& Saito S 2004 Decidual and peripheral blood $\mathrm{CD} 4{ }^{+} \mathrm{CD} 25^{+}$regulatory $\mathrm{T}$ cells in early pregnancy subjects and spontaneous abortion cases. Molecular Human Repoduction 10 347-353. (doi:10.1093/molehr/gah044)

Sasaki Y, Darmochwal-Kolarz D, Suzuki D, Sakai M, Ito M, Shima T, Shiozaki A, Rolinski J \& Saito S 2007 Proportion of peripheral blood and decidual $\mathrm{CD} 4(+) \mathrm{CD} 25$ (bright) regulatory $\mathrm{T}$ cells in pre-eclampsia. Clinical and Experimental Immunology 149 139-145. (doi:10.1111/j. 1365-2249.2007.03397.x)

Seong SY \& Matzinger P 2004 Hydrophobicity: an ancient damageassociated molecular pattern that initiates innate immune responses. Nature Reviews Immunology 4 469-478. (doi:10.1038/nri1372)

Shen H, Goodall JC \& Hill Gaston JS 2009 Frequency and phenotype of peripheral blood Th17 cells in ankylosing spondylitis and rheumatoid arthritis. Arthritis and Rheumatism 60 1647-1656. (doi:10.1002/art. 24568)

Somerset DA, Zheng Y, Kilby MD, Sansom DM \& Drayson MT 2004 Normal human pregnancy is associated with an elevation in the immune suppressive $\mathrm{CD}_{2} 5^{+} \mathrm{CD}^{+}$regulatory T-cell subset. Immunology $\mathbf{1 1 2}$ 38-43. (doi:10.1111/j.1365-2567.2004.01869.x)

Sunami R, Komuro M, Yuminamochi T, Hoshi K \& Hirata S 2010 Fetal cell microchimerism develops through the migration of fetus-derived cells to the maternal organs early after implantation. Journal of Reproductive Immunology 84 117-123. (doi:10.1016/j.jri.2009.11.006)

Tafuri A, Alferink J, Moller P, Hammerling GJ \& Arnold B 1995 T cell awareness of paternal alloantigens during pregnancy. Science $\mathbf{2 7 0}$ 630-633. (doi:10.1126/science.270.5236.630)

Taylor DD \& Gercel-Taylor C 2005 Tumour-derived exosomes and their role in cancer-associated T-cell signalling defects. British Journal of Cancer 92 305-311. (doi:10.1038/sj.bjc.6602316)

Taylor DD, Akyol S \& Gercel-Taylor C 2006 Pregnancy-associated exosomes and their modulation of $\mathrm{T}$ cell signaling. Journal of Immunology 176 1534-1542.

Tilburgs T, Roelen DL, van der Mast BJ, de Groot-Swings GM, Kleijburg C, Scherjon SA \& Claas FH 2008 Evidence for a selective migration of 
fetus-specific $\mathrm{CD} 4{ }^{+} \mathrm{CD} 25$ bright regulatory $\mathrm{T}$ cells from the peripheral blood to the decidua in human pregnancy. Journal of Immunology $\mathbf{1 8 0}$ 5737-5745.

Tilburgs T, Scherjon SA, van der Mast BJ, Haasnoot GW, Versteeg VDVMM, Roelen DL, van Rood JJ \& Claas FH 2009 Fetal-maternal HLA-C mismatch is associated with decidual T cell activation and induction of functional T regulatory cells. Journal of Reproductive Immunology 82 148-157. (doi:10.1016/j.jri.2009.05.003)

Urabe S, Miyoshi H, Fujiwara H, Yamaoka K \& Kudo Y 2009 Enhanced expression of $\mathrm{P} 2 \mathrm{X} 4$ and $\mathrm{P} 2 \mathrm{X} 7$ purinergic receptors in the myometrium of pregnant rats in preterm delivery models. Reproductive Sciences $\mathbf{1 6}$ 1186-1192. (doi:10.1177/1933719109344630)

Vacca P, Cantoni C, Vitale M, Prato C, Canegallo F, Fenoglio D, Ragni N, Moretta L \& Mingari MC 2010 Crosstalk between decidual NK and CD14 ${ }^{+}$myelomonocytic cells results in induction of Tregs and immunosuppression. PNAS 107 11918-11923. (doi:10.1073/pnas.1001749107)

Wegmann TG, Lin H, Guilbert L \& Mosmann TR 1993 Bidirectional cytokine interactions in the maternal-fetal relationship: is successful pregnancy a TH2 phenomenon? Immunology Today 14 353-356. (doi:10.1016/0167-5699(93)90235-D)

Wilczynski JR, Tchorzewski H, Banasik M, Glowacka E, Wieczorek A, Lewkowicz P, Malinowski A, Szpakowski M \& Wilczynski J 2003 Lymphocyte subset distribution and cytokine secretion in third trimester decidua in normal pregnancy and preeclampsia. European Journal of Obstetrics \& Gynecology and Reproductive Biology 109 8-15. (doi:10. 1016/S0301-2115(02)00350-0)
Williams PJ, Bulmer JN, Searle RF, Innes BA \& Robson SC 2009 Altered decidual leucocyte populations in the placental bed in pre-eclampsia and foetal growth restriction: a comparison with late normal pregnancy. Reproduction 138 177-184. (doi:10.1530/REP-09-0007)

Zenclussen AC, Gerlof K, Zenclussen ML, Sollwedel A, Bertoja AZ, Ritter T, Kotsch K, Leber J \& Volk HD 2005 Abnormal T-cell reactivity against paternal antigens in spontaneous abortion: adoptive transfer of pregnancy-induced $\mathrm{CD}^{+}{ }^{+} \mathrm{CD} 25^{+} \mathrm{T}$ regulatory cells prevents fetal rejection in a murine abortion model. American Journal of Pathology 166 811-822. (doi:10.1016/S0002-9440(10)62302-4)

Zenclussen ML, Thuere C, Ahmad N, Wafula PO, Fest S, Teles A, Leber A, Casalis PA, Bechmann I, Priller J et al. 2010 The persistence of paternal antigens in the maternal body is involved in regulatory T-cell expansion and fetal-maternal tolerance in murine pregnancy. American Journal of Reproductive Immunology 63 200-208. (doi:10.1111/j.1600-0897. 2009.00793.x)

Received 22 August 2010

First decision 27 September 2010

Revised manuscript received 8 February 2011

Accepted 9 March 2011 